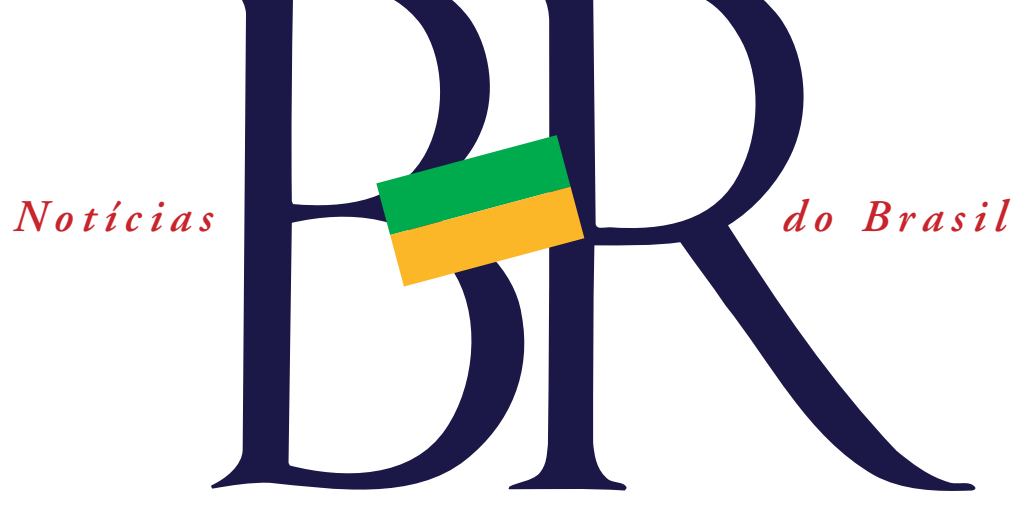

Deputados, outro no Senado e outro no Ministério da Justiça. "A última versão que vi do da Câmara é muito pobre, é incorporado por agências de publicidade", analisa Joana. Até o momento, o texto provavelmente mais conhecido sobre a proteção de dados pessoais é o anteprojeto de lei apresentado pelo Ministério da Justiça, no último dia 20 de outubro e é fruto de cinco anos de discussão, incluindo a incorporação de sugestões pós consulta pública. Em sua mais recente versão, o texto destaca que a lei tem como objetivos assegurar o livre desenvolvimento da personalidade, além da liberdade, intimidade e privacidade. Bruno Bioni avalia positivamente a nova versão, mas avalia que há disparidade regulatória entre o setor privado, mais avançado, e o setor estatal. "Ainda se fala de um órgão competente fiscalizador, mas não diz qual seria o arranjo dele", explica. Teme-se que a medida regulatória punitiva possa prejudicar a liberdade de expressão ao inibir opiniões críticas. Não por outro motivo, documentos e recomendações internacionais indicam que tais atos ilícitos deveriam ser deslocados para a esfera civil", propõe Bruno Bioni.

Sarah Schmidt

Aposentadoria

\section{A vida universitária após os 70 anos}

O prolongamento da carreira dentro da universidade não é exclusividade de alguns professores. $\mathrm{O}$ número de docentes que continua atuando com idade superior a 65 anos é de 14.232 em um total de 71,2 mil, de acordo com o último censo divulgado pelo Ministério da Educação (MEC) e realizado em 2013. Na faixa dos 60 aos 64 anos são 20.548 em exercício. $\mathrm{Na}$ Universidade de São Paulo (USP), o número de professores cadastrados no programa Sênior é de 611. Um cálculo realizado pela universidade prevê que em 2017, $40 \%$ dos seus professores estarão aptos a se aposentar.

Em 8 de setembro, aos 87 anos, José Goldemberg assumiu a presidências da maior financiadora estadual de pesquisa do país, a Fundação de Amparo à Pesquisa do Estado de São Paulo (Fapesp). Ao longo de sua carreira, o físico assumiu diversos cargos administrativos como a presidência da Companhia Energética de São Paulo (CESP); da Sociedade Brasileira para o Progresso da Ciência (SBPC) e cargos públicos como secretário de Ciência e Tecnologia e Meio Ambiente, da Presidência da República. Após mais de seis décadas de atuação na universidade não lhe falta inspiração. "Sou cientista. Vivo preocupado com novos desafios", diz. A maior disponibilidade tecnológica e o melhor preparo dos alunos, na visão de Goldemberg, também tem ajudado o avanço das pesquisas e o aprendizado dele, que se sente aluno dos seus estudantes quando o assunto é domínio de tecnologia. Goldemberg não gosta de falar em aposentadoria e conta que, desde cedo, já tinha para si que jamais iria se aposentar. Para ele, a lei que obriga docentes a se aposentarem aos 70 anos é muito antiga e de quando a expectativa de vida dos brasileiros estava muito abaixo da idade. Ele vê como positiva a possibilidade de ampliação para 75 anos, que já pode ser aplicada aos ministros do Superior Tribunal Federal (STF), como idade compulsória para aposentadoria. Atualmente, ele tem sete orientandos, é co-presidente do International Institute For Applied Systems Analysis (IIASA), na Áustria, coordena três projetos de pesquisa e um de desenvolvimento, é revisor de vários periódicos e membro do conselho de outros e autor de 22 artigos apenas nos últimos 5 anos.

INOVAÇÃO E CRIATIVIDADE Aos 77 anos o físico Sérgio Mascarenhas, hoje com 87 anos, recebeu o diagnóstico de que estava com hidrocefalia, um acúmulo de líquido dentro do crânio que pode causar danos ao cérebro, e que seria necessário realizar um exame de perfuração para medir a pres- 


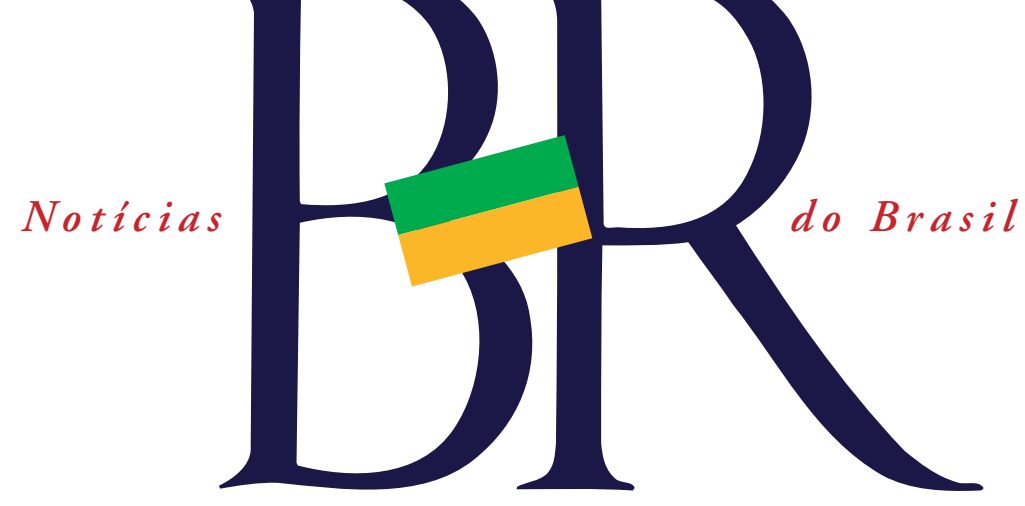

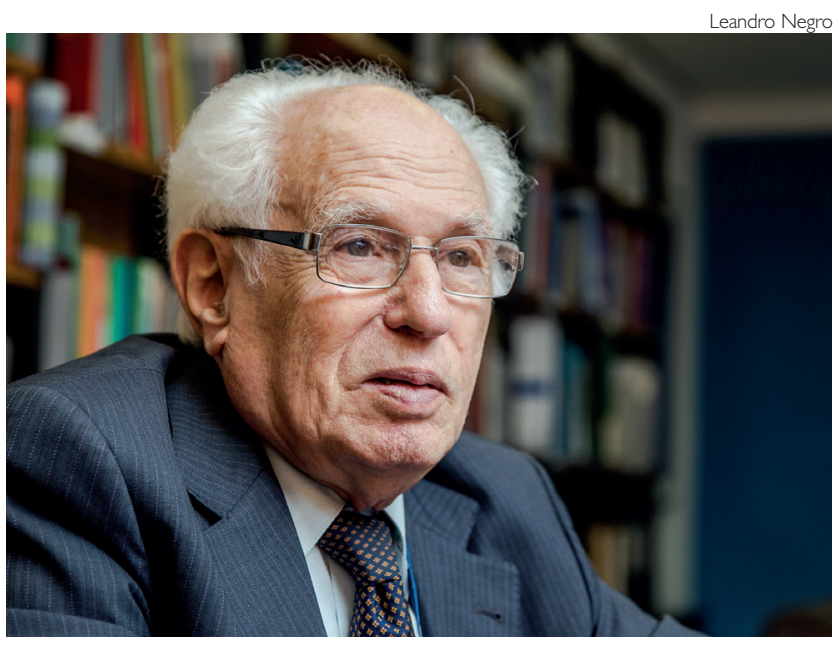

Goldemberg assumiu a presidência da Fapesp aos 87 anos
Estudos Avançados (IEA) da USP em São Carlos.

O insight de Mascarenhas veio três anos antes dele se aposentar compulsoriamente pela universidade. "Aposentar-se é um ato de conformação", define. Para ele, é possível se aposentar de um emprego, mas impossível aposentar-se da cisão intracraniana. Incomodado com a ideia de realizar um exame tão invasivo, mas o único disponível para que pudesse responder à situação da doença, ele passou a imaginar uma forma alternativa de exame.

Os primeiros experimentos foram feitos com um balão de aniversário, pedido ao seu neto, inflado dentro de um crânio emprestado da Faculdade de Medicina da Universidade Federal de São Carlos (UFSCar). Com sensores de medição nas duas partes, ele verificou que os números de pressão na bexiga e no crânio coincidiam. A ideia partiu da observação de uma atividade já corriqueira para os engenheiros que é identificar a vibração interna de pilastras de concreto sem ter que furar a construção. $\mathrm{O}$ teste simples correu como o esperado e a ideia foi levada para o laboratório. Atualmente o sistema está na fase de protótipo e segue sendo desenvolvido pelo Instituto de ência, da educação e do ideal de que uma sociedade melhor é construída por meio de um trabalho em equipe.

PLENA ATIVIDADE Depois de atender ao pedido de entrevista, Myriam Krasilchik, docente da Faculdade de Educação da USP, confessa que resolveu fazer os cálculos de quantos anos lecionava após os 70 , e já se passaram 13. Seu curso de método do ensino superior continua a ser bastante procurado por alunos de diferentes unidades. Além do prazer da vida universitária e o contato rico com colegas, professores, alunos, Myriam também é motivada por querer "continuar contribuindo com o resultado da minha vivência para o aperfeiçoamento da educação".

A docente diz que há fases e em cada uma delas é possível contribuir de uma maneira diferente. Ao longo de sua carreira foi conhecendo toda a universidade ao iniciar a participação em comissões, depois foi diretora da Faculdade de Educação, vice-reitora e, após os 70, foi presidente da comissão de planejamento da USP Leste. Aposentado desde 1995, o professor da Faculdade de Arquitetura e Urbanismo da Universidade Federal da Bahia (UFBA) Pascoalino Magnavita mantém o vínculo com a universidade em meio a uma agenda lotada, entre aulas exposições e viagens. $\mathrm{O}$ engenheiro civil e doutor em arquitetura, possui uma bolsa de produtividade do Conselho Nacional de Desenvolvimento Científico e Tecnológico (CNPq) em seu nível mais alto, ministra aulas e orientações. $\mathrm{O}$ contato com alunos mais jovens e a troca de experiências mantêm seu ânimo com a academia. Assim como considera estimulante a experiência e criatividade dos alunos, ele também considera fundamental e igualmente prazeroso passar uma visão de mundo diferente para os que fogem ao senso comum. "Acho estimulante estar na universidade, onde a gente não ensina o que sabe, mas sim o que pesquisa e estimula os estudantes a pensar diferente". E completa, "Apesar das diferentes sociedades - vivi na sociedade da disciplina e eles vivem na sociedade do controle -, penso de forma jovem, meu pensamento é contemporâneo", diz. 